\title{
Descriptions, notes and new records in south american Cerambycidae (Coleoptera)
}

\author{
Antonio Santos-Silva ${ }^{1,4}$, Francisco Eriberto de Lima Nascimento ${ }^{1,5}$, Alain Drumont ${ }^{2}$ \& Anton Olegovich Kozlov ${ }^{3}$ \\ 1 Universidade de São Paulo (USP), Museu de Zoologia (MZUSP). São Paulo, SP, Brasil. \\ ${ }^{2}$ Royal Belgian Institute of Natural Sciences (RBINS), Entomology Department. Brussels, Belgium. \\ ORCID: http://orcid.org/0000-0001-9357-473X.E-mail: alain.drumont@naturalsciences.be \\ 3 Independent researcher currently not affiliated. Moscow, Russia. E-mail: kant.klintsy@gmail.com \\ ${ }^{4}$ ORCID: http://orcid.org/0000-0001-7128-1418. E-mail: toncriss@uol.com.br \\ ${ }^{5}$ ORCID: http://orcid.org/0000-0002-5047-8921. E-mail: eribnascimentofl@gmail.com
}

\begin{abstract}
Three new species and one new genus are described: Psyrassa lisitskyisp. nov., from Peru (Elaphidiini); Ophtalmibidion antonkozlovi sp. nov., from Colombia (Neoibidionini); and Nappella gen. nov., is proposed to N. antonkozlovi sp. nov., from Peru (Calliini). Epectasis mexicana Breuning, 1954 is redescribed, and figured for the first time, and recorded for Colombia. Psyrassa lisitskyi is included in a modified couplet from a previous key. A key to species of Ophtalmibidion and genera of Calliini are provided. Chorenta biramiguelus is recorded for Peru.
\end{abstract}

Key-Words. Key; Longhorned beetle; South America; Taxonomy.

\section{INTRODUCTION}

Central and South America have a great and complex geobiotic history which reflects in its great biodiversity (Carvalho \& Almeida, 2011). The immense diversity of Cerambycidae can be verified in the "Catalog of Cerambycidae (Coleoptera) of the Neotropical Region", which includes distribution and taxonomic history of the species (Monné, 2018a, b, c)

Recently Anton Olegovich Kozlov (Moscow, Russia), sent several specimens of Cerambycidae, mostly from Mexico, Costa Rica, Peru, and Colombia for study in the MZSP. Through the study of these specimens we found some new species, which are described and illustrated, and establish a new country record. Additionally, we redescribed Epectasis mexicana Breuning, 1954 to provide detailed information for future revisions of this problematic genus with poorly defined species.

\section{MATERIAL AND METHODS}

Photographs were taken with a Canon EOS Rebel T3i DSLR camera, Canon MP-E $65 \mathrm{~mm}$ f/2.8 1-5X macro lens, controlled by Zerene Stacker AutoMontage software. Measurements were taken in "mm" using measuring ocular Hensoldt/ Wetzlar - Mess 10 in the Leica MZ6 stereomicroscope, also used in the study of the specimens.
Only the new species of Psyrassa is described by the four authors. The new genus and the other new species are described by the three first authors. We redescribed Epectasis mexicana based on the holotype and in a second known male.

The acronyms used in the text are as follows:

- AKPC = Anton Kozlov Private Collection, Moscow, Russia

- MZSP = Museu de Zoologia, Universidade de São Paulo, São Paulo, Brazil

- RBINS = Royal Belgian Institute of Natural Sciences, Brussels, Belgium

\section{RESULTS}

\section{Cerambycinae \\ Elaphidiini Thomson, 1864 \\ Psyrassa Pascoe, 1866}

Psyrassa was revised by Toledo (2005). After this, seven species were described. Currently, the genus includes 42 species distributed from southern United States of America to northern South America, including Caribbean islands (Monné, 2018a; Tavakilian \& Chevillotte, 2017).

Martins (2005) characterized the South American species of Psyrassa by the prothorax longer than wide, with III antennomere as long as the IV and with an apical spine, blunt-tipped, almost 
as long as the antennomere, by the center of the pronotum without tubercles and by the sublinear metafemora. In his phylogenetic study, Lingafelter (1998) characterized the genus by the strong basal pronotal constriction, sparsely punctate, pubescent pronotum, procoxal cavities strongly closed and by the short antennomere III.

\section{Psyrassa lisitskyi Santos-Silva, Nascimento, Drumont \& Kozlov, sp. nov.} (Figs. 1-4)

Description: Male. Color. Head blackish, slightly reddish on some areas depending on light intensity; antennae black; pronotum dark reddish brown (more dark-brown depending on light intensity) except black, narrow anterior and posterior areas close to margins; remaining surface of prothorax mostly black with irregular dark reddish-brown areas (slightly distinct depending on light intensity); ventral side of meso- and metathorax black (somewhat dark reddish brown on some areas, depending on light intensity); elytra black centrally from base to near apex (this area narrowed toward apex), dark reddish brown on remaining surface; legs black, slightly reddish on tarsi; abdominal ventrites dark reddish brown, more blackish centrally.

Head: Frontal plate rugose; sides of frons depressed, moderately coarsely, densely punctate laterally; central area moderately coarsely, abundant punctate (punctures smoother than on sides); with minute, sparse yellowish-white setae (more whitish depending on light intensity). Area between antennal tubercles and upper eye lobes moderately finely, smoothly, abundantly punctate except nearly smooth area close to eyes; with minute, sparse yellowish-white setae (more whitish depending on light intensity). Remaining surface of vertex finely, sparsely punctate (denser on central area close to prothoracic margin); with minute, sparse yellowish-white setae (more whitish depending on light intensity), distinctly sparser than on area between antennal tubercles and eyes. Area behind eyes moderately finely, abundantly punctate (less so close to eyes); glabrous except a few minute yellowish-white setae close to inferior side of lower eye lobes. Genae very small (anterior margin of lower eye lobes touching distal margin dorsally), nearly glabrous, rounded apically. Antennal tubercles moderately finely, sparsely punctate except smooth distal area; with minute, sparse yellowish-white setae (more whitish depending on light intensity). Last segment of maxillary and labial palpi slightly widened at basal third, subparallel-sided on remaining surface, with apex obliquely truncate. Median groove distinct from frontal plate to area between upper eye lobes. Postclypeus smooth, distinctly narrow on wide central area; with minute, sparse yellowish-white setae (more whitish depending on light intensity); with one long, erect, translucent yellowish seta on each side of wide central area. Labrum coplanar with anteclypeus on posterior third, inclined on anterior $2 / 3$; nearly glabrous close to anteclypeus, with short golden setae on remaining sur- face. Gulamentum smooth, glabrous between prothoracic margin and posterior margin of lower eye lobes; moderately coarsely, abundantly punctate, with both, short and long yellowish-white setae (more whitish depending on light intensity) between eye lobes. Distance between upper eye lobes 0.51 times length of scape; in frontal view, distance between lower eye lobes 0.80 times length of scape. Antennae (missing antennomeres V-XI of left antennae; missing antennomeres VIII-XI of right antennae - antennomeres V-VII glued on a card) almost reaching posterior third of elytra. Scape moderately coarsely, abundantly punctate dorsally and laterally (punctures denser basally) except smooth posterior area, sparsely punctate ventrally; with short, decumbent, sparse yellowish-white setae dorsally and laterally, sparser, interspersed with a few long, erect setae of same color ventrally. Pedicel with short, sparse yellowish setae, interspersed with long, erect setae of same color ventrally. Antennomere III longitudinally carinate dorsally (carina becoming slightly conspicuous toward apex); moderately finely, shallowly punctate on basal third, opaque, finely rugose on distal 2/3; inner apex with straight spine, acute at apex, 0.55 times as long as widest width of segment; basal third with sparse yellowish-white pubescence, more abundant on distal third except smooth, glabrous apex; ventral side with long, erect, sparse yellowish setae. Antennomere IV opaque, finely rugose throughout; slightly carinate dorsally; with yellowish-white pubescence not obscuring integument, interspersed with long, erect, sparse yellowish setae ventrally; inner apex with minute spine; antennomeres V-VII with sculpturing and pubescence as on IV, with inner apex unarmed. Antennal formula (ratio) based on length of antennomere III (excluding spine): scape $=0.65$; pedicel $=0.19 ; \mathrm{IV}=0.94 ; \mathrm{V}=0.93 ; \mathrm{VI}=0.85 ; \mathrm{VII}=0.82$.

Thorax: Prothorax 1.15 times longer than wide; posterior constriction well-marked; anterior constriction slightly distinct; sides nearly parallel-sided between constrictions, slightly widened toward posterior constriction. Pronotum coarsely, moderately sparsely punctate (punctures slightly denser toward sides); with minute yellowish-white setae emerging from some punctures. Sides of prothorax moderately coarsely and abundantly punctate between anterior and posterior constrictions, transversely striate from margins to constrictions (more so anteriorly); with a few long, erect yellowish setae anteriorly. Prosternum rugose-punctate on about posterior $2 / 3$, transversely striate on anterior third (interspersed with a few punctures); with sparse yellowish-white pubescence on rugose-punctate area, interspersed with a few long whitish setae; with short, decumbent, very sparse whitish setae on anterior third, interspersed with a few long, erect setae of same color. Procoxal cavities distinctly open posteriorly. Ventral side of mesothorax with yellowish-white pubescence (more grayish-white depending on light intensity), distinctly denser than on prosternum. Mesoventral process centrally emarginate at apex, with apical sides projected under mesocoxal cavities. Metanepisternum and narrow lateral area of metaventrite with yellowish-white pubescence not obscuring 

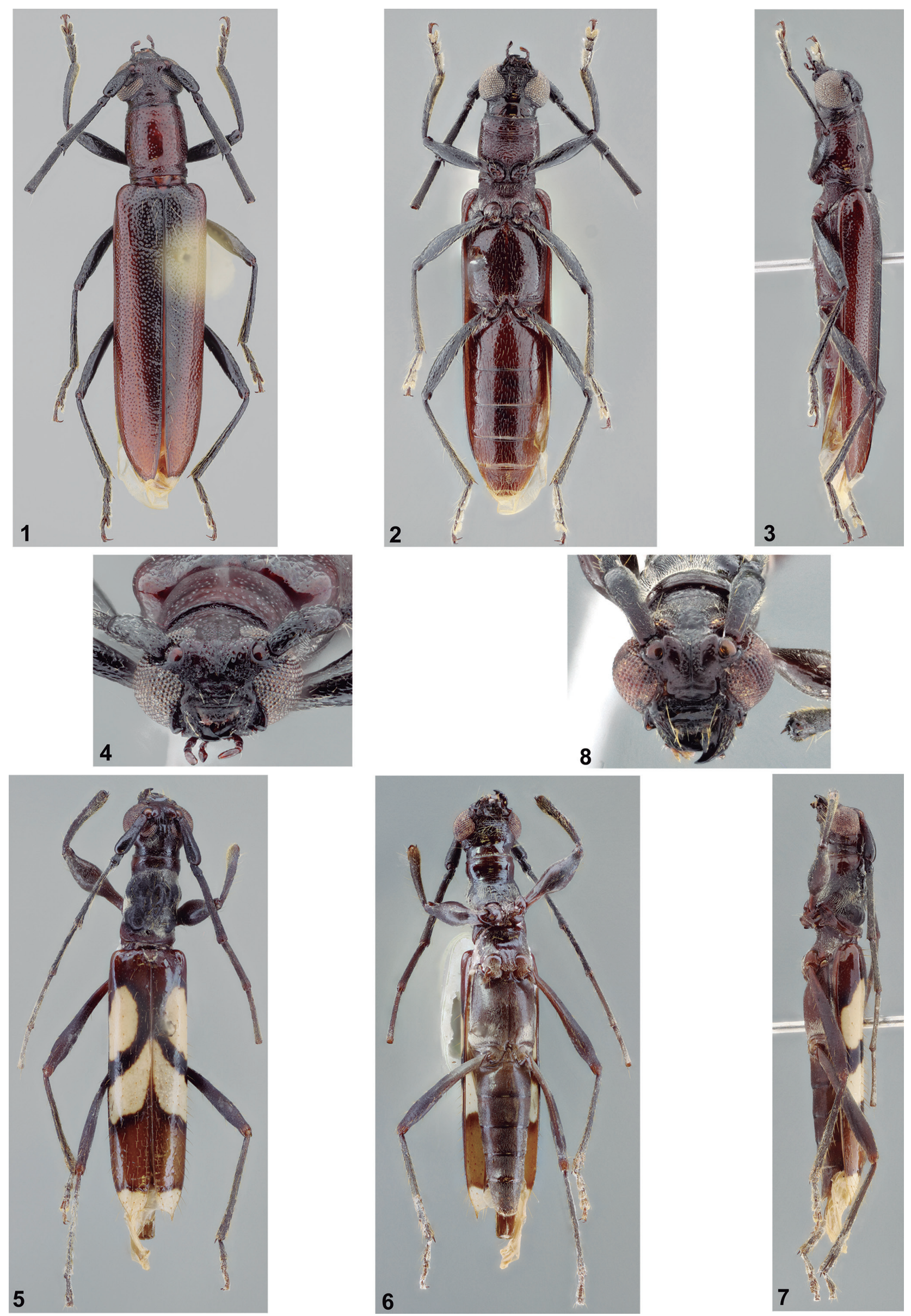

Figures 1-8. (1-4) Psyrassa lisitskyi, holotype male: (1) Dorsal habitus; (2) Ventral habitus; (3) Lateral habitus; (4) Head, frontal view. (5-8) Ophtalmibidion antonkozlovi, holotype female: (5) Dorsal habitus; (6) Ventral habitus; (7) Lateral habitus; (8) Head, frontal view. 
integument; remaining surface of metaventrite with moderately long, decumbent, sparse yellowish-white setae; metaventrite moderately finely, sparsely punctate throughout (punctures slightly more abundant laterally). Scutellum with abundant yellowish-white pubescence not obscuring integument. Elytra: Coarsely, abundantly punctate (punctures slightly finer and sparser on distal third); with minute, yellowish-white setae emerging from nearly all punctures, and a few long, erect yellowish setae emerging from some punctures; apex obliquely truncate emarginate, with apex of outer angle rounded, and apex of sutural angle acute. Legs: Femora moderately sparsely punctate (punctures denser posteriorly); with short, decumbent, sparse yellowish-white setae dorsally and laterally, interspersed with a few long, erect setae of same color; with long yellowish setae ventrally, bristly, more abundant on basal third. Tibiae with short, sparse yellowish setae dorsally, interspersed with a few long, erect setae of same color; with moderately abundant, bristly yellowish setae ventrally, gradually denser toward apex, interspersed with long, erect setae of same color. Metatarsomere I about as long as II-III together.

Abdomen: Ventrites moderately finely and sparsely punctate; with both short and long, decumbent yellowish setae distinctly not obscuring integument; apex of ventrite $\mathrm{V}$ slightly concave.

Dimensions in mm (holotype male): Total length, 12.95; prothoracic length, 2.10; anterior prothoracic width, 1.55; posterior prothoracic width, 1.70; widest prothoracic width, 1.85; humeral width, 2.65; elytral length, 8.75 .

Type material: Holotype male from PERU, La Libertad: Sánchez Carrión (Road PE10C, km 109, near Chagual, 1,300 m, 0753.17'S, 77³7.25'W), 21.XII.2016, V. Sinyaev col. (MZSP, former AKPC).

Etymology: The new species is named to honor Victor Nikitovich Lisitsky, a retired Soviet gymnast, who competed in all artistic gymnastics events in the 1964 and 1968 Summer Olympics, and won five silver medals, three individual in 1964 and two with the Soviet team, in 1964 and 1968. He is a personal friend of the fourth author, who chose the name of the species.

Remarks: Currently, six species of Psyrassa Pascoe, 1866 are known from South America (Monné, 2018a), none of them occurring in Peru: P. ludmilakozlovae SantosSilva et al., 2017; P. meridionalis Martins, 2005; P. rufescens Nonfried, 1894; P. subglabra Linsley, 1935; P. testacea Linsley, 1935; and P. unisucre Santos-Silva et al., 2017. Psyrassa lisitskyi sp. nov., differs from P. ludmilakozlovae by the spine of inner apex of the antennomere III straight and distinctly shorter than maximum width of the antennomere, antennomere IV with minute spine at inner apex, antennomeres V-VII unarmed at inner apex, procoxal cavities open posteriorly, and outer elytral apex without spine. In P. ludmilakozlovae, the spine of inner apex of the antennomere III is curved and distinctly longer than maximum width of the antennomere, antennomere IV has long spine at inner apex, antennomeres V-VII have distinct spine at inner apex, procoxal cavities are closed posteriorly, and the outer elytral apex has distinct spine. It differs from P. meridionalis by the spine of antennomere III distinctly shorter (longer than maximum width of the antennomere in P. meridionalis), apex of antennomere IV with spicule (with distinct spine in P. meridionalis), and procoxal cavities open posteriorly (closed in P. meridionalis). According to Martins (2005), Toledo (2005), and SantosSilva et al. (2017), P. rufescens evidently does not belong to Psyrassa, especially by the prothorax "obtuse spinosis" laterally, and "quinquegibbosus" dorsally. Unfortunately, the holotype may be lost forever (Martins, 2005). Psyrassa lisitskyi differs from $P$. subglabra by the color of the pronotum not notably contrasting to that of the elytra (contrasting in P. subglabra), antennomere IV with spicule at apex (with distinct spine in $P$. subglabra), and elytral apex without spine (with long outer spine in P. subglabra). The new species differs from $P$. testacea by the spine of antennomere III distinctly shorter than maximum width of the antennomere (distinctly longer in P. testacea), antennomere IV with spicule at apex (with distinct spine in $P$. testacea), antennomere $\mathrm{V}$ unarmed at apex (with spine in P. testacea), pronotum without long and erect setae (present in P. testacea), and procoxal cavities open posteriorly (closed in P. testacea). Psyrassa lisitskyi differs from $P$. unisucre by the spine of antennomere III distinctly shorter than maximum width of the antennomere (noticeably longer in $P$. unisucre), antennomere IV with spicule at apex (with long spine in $P$. unisucre), antennomeres V-VII unarmed at apex (with distinct spine in $P$. unisucre), procoxal cavities open posteriorly (closed in P. unisucre), and elytral apex not bispinose (bispinose in $P$. unisucre).

\section{Psyrassa lisitskyi can be included in the alternative of couplet "19" from Toledo (2005) (translated):}

19'(18). Elytra not pubescent. Peru P. lisitskyi sp. nov.

- Elytra distinctly pubescent 19

$19\left(19^{\prime}\right)$. Integument of the body from dark brown to black, femora reddish. El Salvador................................................. P. ebenina Linsley, 1935

- Integument of the body from dark to black, prothorax and femora reddish. Mexico ....................... P. levicollis Chemsak \& Noguera, 1993

\section{Neoibidionini Neoibidionina Ophtalmibidion Martins, 1969}

Ophtalmibidion is a small genus of Neoibidionini (Neoibidionina), with four known species distributed only in South America (Monné, 2018a). Martins \& Galileo (2007) revised the genus and provided a key to species.

According to Martins (2007), Ophtalmibidion is characterized by the strong posterior constriction of the head, anterior to prothorax, eyes lobes divided, flagellomeres not widened in the antennae of males, and apices of metafemora disarmed. 


\section{Ophtalmibidion antonkozlovi Santos-Silva, Nascimento \& Drumont, sp. nov.} (Figs. 5-8)

Description: Female. Color. Head dark brown, almost black; prothorax black centrally, slightly dark brown toward anterior and posterior margins; scape and pedicel black; antennomeres dark brown, slightly, gradually lighter toward antennomere VI (missing antennomeres VII-XI of left antenna, and VI-XI of right antenna); ventral side of meso- and metathorax dark brown, slightly reddish on central apex of metaventrite; femora dark brown except reddish-brown basal area; tibiae and tarsi dark brown; abdominal ventrites dark brown except reddish-brown centro basal area of ventrite I. Anterior $2 / 3$ of elytra dark brown (forming darker band around light areas) except two large yellowish-white maculae: one subelliptical, oblique, starting at about anterior eighth of dorsal surface, ending near lateral margin slightly after apex of anterior third; another oblique, placed about midlength, projected forward along suture, ending near lateral margin. Posterior third of elytra reddish brown except apex yellowish-brown and dark brown band between these two areas.

Head: Frontal plate very finely, obliquely striate, divided by moderately deep, oblique sulcus on each side of median groove; with longitudinal sulcus laterally between frontal plate and lower eye lobes; finely, moderately abundantly punctate centrally toward antennal tubercles; with short, erect, sparse brownish setae close to eyes, glabrous on remaining surface. Area between antennal tubercles shallowly, moderately finely punctate; glabrous. Area between upper eye lobes with U-shaped, slightly elevated carina; finely, moderately abundantly punctate close to eyes, smooth on remaining surface; surface glabrous. Remaining surface of vertex minutely, densely punctate except area close to prothorax finely, moderately sparsely punctate; area minutely punctate with yellowish-brown pubescence not obscuring integument centrally, more yellowish-white laterally; area close to prothorax nearly glabrous. Area behind upper eye lobes sulcate close to eye, minutely, densely punctate between sulcus and finely, moderately sparsely punctate area close to prothorax; with moderately dense yellowish-white pubescence close to eye, glabrous close to prothorax; with a few long, erect yellowish-setae close to eye. Area behind lower eye lobes tumid, finely, moderately abundantly punctate close to eye, nearly smooth on remaining surface; with sparse, erect, yellowish setae on tumid area, glabrous on remaining surface. Genae minutely, densely punctate except smooth distal area; with minute, sparse, decumbent yellowish setae except glabrous smooth area. Median groove distinct from oblique sulcus of frontal plate to area between upper eye lobes (carinate between antennal tubercles and eyes). Postclypeus nearly glabrous except a few short, erect, yellowish setae on sides of wide central area, interspersed with one long, erect setae of same color on each side. Labrum coplanar with anteclypeus on posterior third, inclined on anterior $2 / 3$; with long, erect, nearly golden setae, especially laterally. Gulamentum smooth and glabrous on posterior third, tumid, moderately finely punctate on anterior $2 / 3$; glabrous on smooth area, with long, erect and decumbent, moderately yellowish setae on tumid area. Distance between upper eye lobes 0.26 times length of scape; in frontal view, distance between lower eye lobes 0.62 times length of scape; upper eye lobes with three rows of ommatidia; connection between eye lobes with row of one ommatidium. Antennae almost reaching posterior third of elytra (apex of antennomere VI); scape with yellowish-brown pubescence not obscuring integument, interspersed with a few long, erect yellowish setae, except glabrous distal area; pedicel and antennomeres with yellowish-white pubescence not obscuring integument, and long, erect yellowish setae ventrally, sparser toward antennomere Vl; antennal formula (ratio) based on antennomere III: scape $=0.68$; pedicel $=0.12 ; \mathrm{IV}=0.75 ; \mathrm{V}=0.85 ; \mathrm{VI}=0.81$.

Thorax: Prothorax cylindrical, 1.5 times longer than wide; sides bigibbous centrally; anterior and posterior constrictions well-marked. Pronotum with five large gibbosities between anterior and posterior constrictions, one anterior and one posterior subcircular gibbosity on each side, another subelliptical centrally; somewhat rugose centrally, including part of central gibbosity; coarsely, very sparsely punctate; posterior sulcus well-marked; with grayish-white pubescence not obscuring integument, distinctly sparser close to anterior margin, denser, yellower centrally between lateral gibbosities of posterior area, between lateral gibbosities, and on area of anterior constriction; with long, erect, sparse yellow setae. Sides of prothorax with dense yellowish-white pubescence on posterior $2 / 3$ (more whitish depending on light intensity), nearly glabrous on anterior third (this area widened toward ventral side); with a few long, erect, yellowish setae. Prosternum moderately coarsely, sparsely punctate on posterior half, finely, transversely, finely striate on anterior half; with moderately dense grayish-white pubescence on posterior half, interspersed with long, erect yellowish setae, glabrous on anterior half. Mesoventrite with very sparse grayish-white (more yellowish depending on light intensity) pubescence centrally, denser laterally; mesanepisternum, mesepimeron, and metanepisternum with grayish-white pubescence partially obscuring integument (more yellowish depending on light intensity). Mesoventral process centrally emarginate at apex, with apical sides projected under mesocoxal cavities. Metaventrite with grayish-white pubescence, denser close to metacoxae (more yellowish depending on light intensity). Scutellum with yellowish-white pubescence not obscuring integument. Elytra: Finely, sparsely punctate; with minute, very sparse yellowish-white setae interspersed with long, erect yellowish setae throughout, more abundant on distal half; apex obliquely truncate, with long spine at outer angle, and rounded sutural angle. Legs: Missing protarsi, right middle leg, and left metatarsomeres III-V. Femora and tibiae with grayish-white pubescence partially obscuring integument, interspersed with long, erect yellow setae, denser, bristly on ventral side of distal third of tibiae. 
Abdomen: Ventrites with grayish-white pubescence partially obscuring integument; ventrites III-V with a few long, erect yellowish-brown setae; apex of ventrite $\checkmark$ rounded.

Dimensions (mm): Total length, 12.25; prothoracic length, 2.50; anterior prothoracic width, 1.35; posterior prothoracic width, 1.60; widest prothoracic width, 1.65; humeral width, 2.15; elytral length, 7.60.

Type material: Holotype male from COLOMBIA, La Guarija: Carretera Via Palomino-Mingueo (Cabañas El Bosque; $\left.55 \mathrm{~m} ; 11^{\circ} 13^{\prime} 00^{\prime \prime} \mathrm{N}, 73^{\circ} 28^{\prime} 29^{\prime \prime} \mathrm{W}\right)$, no date indicated, Sinyaev col. (MZSP, former AKPC).

Etymology: The new species is named to honor Anton Olegovich Kozlov, who sent the specimens for study, and donated the holotype for the MZSP collection.

Remarks: Ophtalmibidion antonkozlovi, sp. nov., is similar to O. auba Martins \& Galileo, 1999, but differs as follows: antennae and legs dark (from black to dark-brown); anterior half of the elytra dark brown between light areas; anterior third of the elytra without oblique pale yellow macula; outer angle of the elytral apex spiniform. In O. auba, the antennae and legs are yellowish-brown, anterior half of the elytra is yellowish-brown between the light areas, anterior third of the elytra with oblique pale yellow macula, and the outer angle of the elytral apex is slightly projected.

\section{Key to species of Ophtalmibidion (modified from Martins \& Galileo, 2007)}

1. Elytra without whitish macula on apex. Brazil (Mato Grosso do Sul, Espírito Santo) ........................ Ophtalmibidion luscum Martins, 1971

Elytra with whitish macula on apex.

....2

2(1). Pronotum not pubescent. Brazil (Espírito Santo)

0. oculatum Martins, 1969

Pronotum pubescent.

3(2). Anterior half of the elytra mostly reddish brown, and posterior half mostly dark brown (between whitish maculae). Peru, Brazil (Pará, Mato Grosso, Mato Grosso do Sul, Minas Gerais, São Paulo, Paraná), Bolivia, Argentina (Misiones) 0. tetrops (Bates, 1870) Posterior half of elytra not dark brown (between whitish maculae)... 4

4(3). Antennae and legs dark; anterior half of the elytra mostly dark brown, and posterior half mostly reddish brown. Colombia

0. antonkozlovi sp. nov.

Antennae and legs yellowish brown; anterior half of the elytra yellowish brown (between whitish maculae). Brazil (Amazonas) .... 0. auba Martins \& Galileo, 1999

\section{Lamiinae}

Caliiini Thomson, 1864

Currently, American Calliini includes 178 species distributed in 40 genera (Monné, 2018b). The tribe was re- vised by Galileo \& Martins (1991), but new genera and species were described posteriorly.

\section{Nappella Santos-Silva, Nascimento \& Drumont, gen. nov.}

Type species: Nappella antonkozlovi new species, current designation.

Etymology: Surname of the late Dr. Dilma Solange Napp + "-ella", Latin, used to form a diminutive, indicating small size. Feminine gender.

Description: Frons transverse. Eyes coarsely faceted; lower eye lobes about 3.5 times genal length; distance between upper eye lobes shorter than maximum width of one upper eye lobe. Scape without apical cicatrix; slightly, gradually widened toward apex, shorter than antennomere III. Antennomeres filiform, cylindrical (III-VI cylindrical, slightly widened toward apex), without long and dense setae ventrally; antennomere III slightly longer than IV. Prothorax transverse, with small, acute tubercle laterally, placed at about midlength. Pronotum with three slightly conspicuous gibbosities. Prosternal process notably narrow centrally. Mesoventral process not tuberculate. Elytra convex, without carinae, not depressed along suture, parallel-sided, pubescent; humerus rounded; elytral length about 2.5 times humeral width; apex nearly rounded; with erect setae throughout. Femora slightly clavate, profemora less so; apex of metafemora reaching about middle of ventrite III. Mesotibiae not notched dorsally. Metatarsomere I slightly longer than II-III together.

Remarks: The general appearance of Nappella gen. nov., resembles that of Colombicallia Galileo \& Martins, 1992, Graminea Thomson, 1864, Callia Audinet-Serville, 1835, Callisema Martins \& Galileo, 1990, Drycothaea Bates, 1881, Eumathes Thomson, 1868, and Hirticallia Galileo \& Martins, 1990. Nappella differs from Callisema, Drycothaea, and Eumathes by the mesoventral process lacking a tubercle (tuberculate in these three genera). It differs from Graminea by the scape lacking an apical cicatrix (present in Graminea). The new genus can be separated from Callia especially by having the eyes coarsely faceted (finely faceted in Callia). It can be separated from Hirticallia, which also has eyes coarsely faceted, by the slender body, with elytral length about 2.5 times humeral width (body stouter, with elytral length about 2.0 times humeral width in Hirticallia), prothoracic lateral tubercle short and not spiniform (long and spiniform in Hirticallia), and elytra with short erect setae (distinctly long in Hirticallia). Finally, Nappella differs from Colombicallia by the slender body (wider in Colombicallia), distance between upper eye lobes smaller than half of the width of one upper lobe (from equal to larger in Colombicallia), prosternal process notably narrow (about $1 / 3$ of procoxal cavity in Colombicallia), and mesoventral process narrower than half of width of mesocoxal cavity (wider than half of mesocoxal cavity in Colombicallia). 

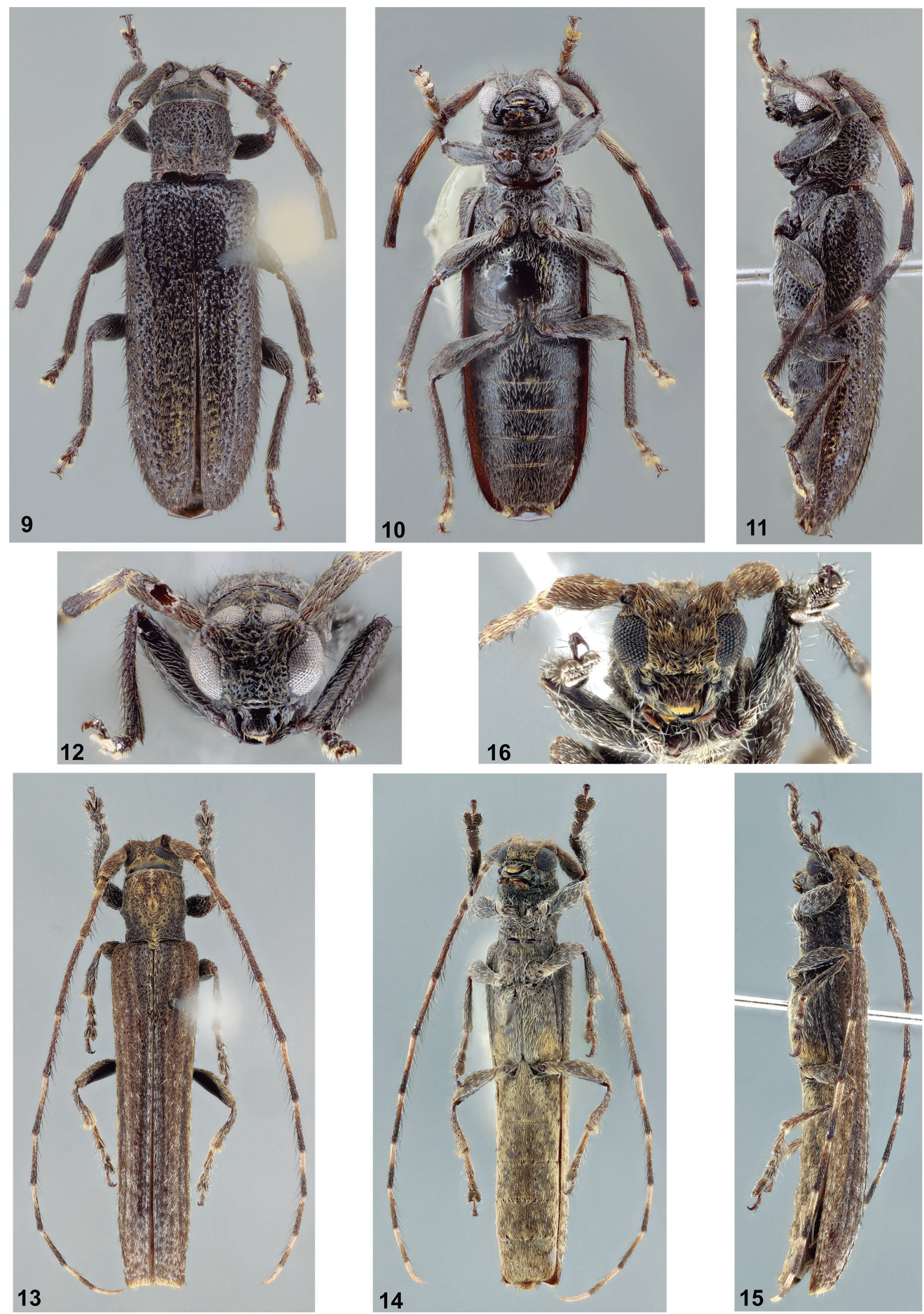

Figures 9-16. (9-12) Nappella antonkozlovi, holotype male: (9) Dorsal habitus; (10) Ventral habitus; (11) Lateral habitus; (12) Head, frontal view. (13-16) Epectasis mexicana, male from Colombia: (13) Dorsal habitus; (14) Ventral habitus; (15) Lateral habitus; (16) Head, frontal view. 


\section{Nappella antonkozlovi Santos-Silva, Nascimento \& Drumont, sp. nov.} (Figs. 9-12)

Description: Male. Color. Integument mostly black; basal half of antennomere III, basal third of IV, and basal quarter of V-VI light brown.

Head: Frons coarsely, abundantly punctate; with yellowish-brown pubescence not obscuring integument, denser laterally and toward antennal tubercles, interspersed with long, erect dark-brown setae. Area between antennal tubercles and upper eye lobes coarsely, abundantly punctate; with yellowish-brown pubescence not obscuring integument, interspersed with a few long, erect dark-brown setae. Remaining surface of vertex and area behind upper eye lobes nearly smooth; with yellowish-brown pubescence partially obscuring integument close to punctate area of vertex and upper eye lobes, sparser toward prothorax on center of vertex, nearly absent toward prothorax behind upper eye lobes; with a few long, erect dark-brown setae close to upper eye lobes. Area behind lower eye lobes moderately finely punctate close to eye, smooth toward prothorax except slightly elevated, longitudinal carina at about middle; with yellowish-brown pubescence nearly obscuring integument close to eyes, glabrous toward prothorax; with a few long, erect, dark-brown setae near inferior side of eye. Genae minutely, transversely striate-punctate; with sparse yellowish-brown pubescence. Antennal tubercles moderately elevated; minutely, densely punctate; with moderately dense yellowish-brown pubescence not obscuring integument, interspersed with long, erect dark-brown setae. Median groove distinct between antennal tubercles and upper eye lobes. Postclypeus with punctures as on frons on wide central area close to frons, smooth toward anteclypeus and laterally; with yellowish-white pubescence partially obscuring integument on punctate area, sparser toward anteclypeus, glabrous laterally; with a few long, erect dark-brown setae laterally on punctate area. Labrum coplanar with anteclypeus at posterior $2 / 3$, inclined at anterior third; finely, moderately abundantly punctate; with yellowish-brown pubescence not obscuring integument, interspersed with long, erect, thick yellowish setae; with fringe of yellow setae at anterior margin. Gulamentum strongly inclined anteriorly; with sparse yellowish-brown pubescence on inclined area, glabrous on remaining surface. Distance between upper eye lobes 0.16 times length of scape; in frontal view, distance between lower eye lobes 0.63 times length of scape. Antennae (missing antennomeres VII-XI of both antennae; right scape damaged) about as long as elytra, apex of antennomere $\mathrm{VI}$ almost reaching distal third of elytra. Antennal formula (ratio) based on length of antennomere III: scape $=0.87$; pedicel $=0.14$; IV $=0.94$; $\mathrm{V}=0.83 ; \mathrm{VI}=0.77$.

Thorax: Prothorax 1.4 times wider than long (including lateral tubercles). Pronotum coarsely, abundantly, partially confluently punctate throughout; with yellowish-brown pubescence not obscuring integument slightly denser on longitudinal band on center of posterior half; with long, erect, sparse yellowish-brown setae throughout. Sides of prothorax with pubescence and sculpturing as on pronotum. Prosternum coarsely, moderately sparsely, deeply punctate except on sulcate area close to anterior margin; with yellowish-white pubescence not obscuring integument except glabrous area close to anterior margin. Central area of prosternal process narrower than 0.1 times width of procoxal cavity. Ventral side of meso- and metathorax moderately coarsely and abundantly punctate except nearly smooth central area of metaventrite; with yellowish-white pubescence not obscuring integument. Mesoventral process about 0.4 times width of mesocoxal cavity. Scutellum nearly smooth, with short, sparse, decumbent yellowish-brown setae. Elytra: Coarsely, abundantly punctate throughout; with yellowish-brown pubescence not obscuring integument, interspersed with long, erect, thick, moderately abundant dark setae throughout. Legs: Femora with yellowish-white pubescence not obscuring integument, interspersed with a few long, erect dark setae. Protibia moderately abruptly widened at distal third; meso- and metatibiae slightly, gradually widened toward apex; with bristly yellowish-brown setae interspersed with long, erect dark setae.

Abdomen: Ventrites with yellowish-white pubescence not obscuring integument, gradually more yellowish-brown toward apex of $\mathrm{V}$; apex of ventrite $\mathrm{V}$ truncate, very slightly emarginate centrally.

Dimensions (mm): Total length, 9.45; prothorax: length, 1.50; anterior width, 1.60; posterior width, 1.65; maximum width (between apices of lateral tubercles), 2.05; humeral width, 2.85; elytral length, 6.85 .

Type material: Holotype male from PERU, Junín: near San Ramón (2,100 m; 11 $\left.{ }^{\circ} 5.26^{\prime} \mathrm{S}, 76^{\circ} 24.3^{\prime \prime} \mathrm{W}\right), 01-02 . X I I .2016$, V. Sinyaev col. (MZSP, former AKPC).

Etymology: The new species is named to honor of Anton Olegovich Kozlov, who sent the specimens for study, and donated the holotype for the MZSP collection.

\section{Key to genera of Calliini (adapted from Galileo \& Martins, 1991)}

1. Prothorax without acute tubercle or spine laterally

2(1). Antennomeres III-V with dense fringe of setae on inner side; elytra with maculae and/or bands with dense pubescence..................Gryllica Thomson, 1860

- Antennomeres III-V with sparse setae on inner side; elytra without maculae and/or bands with dense pubescence 
3(2). Scape with apical cicatrix Schiacallia Galileo \& Martins, 1991

- Scape without apical cicatrix.

4(3). Metatarsomere I in male elongated, distinctly longer than II-III together; elytra broadly flattened dorsally on basal half..................Igualda Thomson, 1868

- Metatarsomere I in male shorter or, at most, as long as II-III together; elytra not flattened dorsally

5(4). Mesoventral process tuberculate Parasemolea Martins \& Galileo, 1990

- Mesoventral process not tuberculate

6(5). Mesotibiae not sulcate on outer side; connection between ocular lobes with a single row of ommatidia... Asemolea Bates, 1881

- Mesotibiae deeply sulcate on distal third of outer side; connection between ocular lobes with more than one row of ommatidia... Euryestola Breuning, 1940

7(1). Mesoventral process with one or two tubercles.

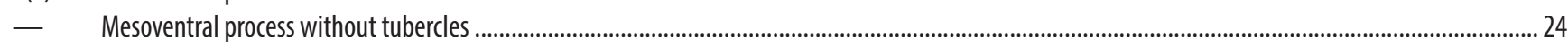

8(7). At least one of the antennomeres flattened and widened toward apex; sometimes several antennomeres widened and projected at apex ........................ 9

- Antennomeres cylindrical, linear; when widened, parallel-sided, without distinct apical or lateral projections............................................................ 12

9(8). Antennomere V strongly expanded

Antennomere V slightly expanded

10(9). Only the antennomere V or V-VI flattened and expanded toward inner side; antennomere VII linear.

- Antennomere IV expanded at apex, V-VII or V-VIII strongly expanded and projected at apex.

11(9). Prothorax transverse, with lateral tubercle large; elytra without dense pubescent maculae. Eumimesis Bates, 1866

- Prothorax as wide as long, with lateral spicule; elytra with dense pubescent maculae .. Hemicladus Buquet, 1857

12(8). Mesoventral process with two tubercles Icelastatis Galileo \& Martins, 1991 ... Harringtonia Lane, 1973

(1)

13(12). Basal antennomeres cylindrical, stout $\ldots$

13(12). Basal antennomeres linear, slender $\quad$ B

14(13). Antennomeres III-X with apical angles projected; antennomere IV as long as scape; metatarsus as long as $2 / 3$ of length of the tibiae......Acreana Lane, 1973

- $\quad$ Antennomeres IV-V slightly projected at inner side of the apex; antennomere IV longer than scape; metatarsus as long as half length of the tibiae...

15(13). Elytra not pubescent; scape with apical cicatrix.

Rumuara Martins \& Galileo, 2006

- Elytra pubescent; scape without apical cicatrix.

..Chalcolyne Bates, 1866

16(12). Scape with apical cicatrix

..Drycothaea Thomson, 1868 (part)

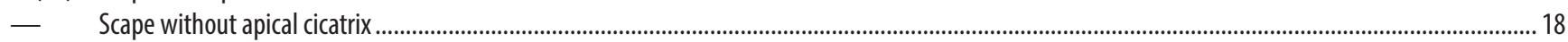

17(16). Elytron depressed along suture ............................................................................................................................lisema Martins \& Galileo, 1990

- Elytron not depressed along suture

Alical Galileo et al., 2017

18(16). Pronotum with 3 tubercles: two anterolateral, another centrobasal; antennomeres VIII-XI yellowish...

- Pronotal tubercles, when present, slightly distinct; distal antennomeres not yellowish...

Canindea Galileo \& Martins, 1990

19(18). Centrobasal area of the elytra depressed on each side of the suture, from base to at least distal curvature ..................................................................... 20

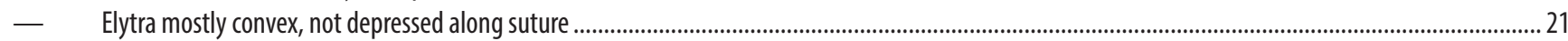

20(19). Each elytron with longitudinal carina on side of dorsal depression; pronotum with golden pubescence..............................................Hastatis Buquet, 1857

— Elytra without longitudinal carina; pronotum without golden pubescence.................................................................................Eumathes Pascoe, 1858

21(19). Integument with distinct metallic reflections.

Miguelia Galileo \& Martins, 1991

- Integument without metallic reflections

22(21). Color pattern uniform, not mimetic with Lampyridae; eyes coarsely faceted

- Color pattern mimetic with Lampyridae; eyes finely faceted.

Drycothaea Thomson, 1868 (part)

23(22). Elytral apex truncate, with outer spicule; metatarsomere I short in male, smaller than II-III together .......

- Elytral apex rounded; metatarsomere I in male distinctly longer than II-III together .

24(7). Scape with apical cicatrix .

…………………………..... 23

Micatocomus Galileo \& Martins, 1988 .Camitocomus Galileo \& Martins, 1991

- Scape without apical cicatrix. .

25(24). General appearance lampyroid.................................................................................................................................Ardeocomus Galileo \& Martins, 1988

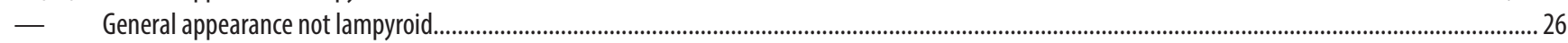

26(25). Mesotibiae deeply sulcate dorsally ............................................................................................................................................ Mimolaia Bates, 1881

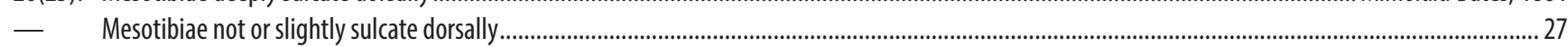

27(26). Antennomere III shorter than IV

- Antennomere III longer than IV.

Cicatricallia Martins \& Galileo, 2012 .. Graminea Thomson, 1864

28(24). Elytra without erect setae Xenocallia Galileo \& Martins, 1990

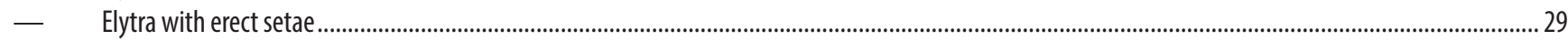

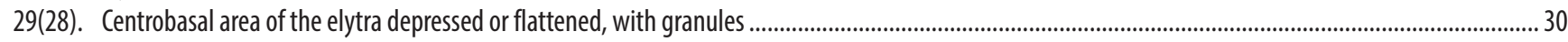

- Centrobasal area of the elytra not depressed or flattened, and without granules ......................................................................................................... 31

30(29). Basal antennomeres tumid, with erect setae concentrated at apex; general appearance lampyroid...

- Basal antennomeres not tumid, with sparse, erect setae on inner side; general appearance not lampyroid

Zenicomus Thomson, 1868

31(29). Basal tooth of the claws reduced; antennomeres III-IV with long and dense erect setae throughout... Chereas Thomson, 1864

- Basal tooth of the claws not reduced; erect setae of the antennomeres sparse or uniformly distributed .Callityrinthia Galileo \& Martins, 1991

32(31). General appearance lampyroid.. 
- General appearance not lampyroid

33(32). Antennomeres tumid; lateral tubercle of the prothorax placed at about midlength..

. Anapsicomus Galileo \& Martins, 1988

Antennomeres not tumid; lateral tubercle of the prothorax placed at posterior third

Lustrocomus Martins \& Galileo, 1996

34(32). Eyes coarsely faceted.

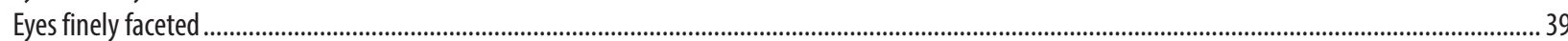

35(34). Lateral tubercle of the prothorax slender, spiniform...

Hirticallia Galileo \& Martins, 1990

- $\quad$ Lateral tubercle of the prothorax not slender and/or spiniform. ... 36

36(35). Body slender, elytra about 2.5 times longer than humeral width Nappella gen. nov. Body stout, elytra, at most, slightly longer than 2.0 times humeral width

37(36). Elytra shorter than 2.0 times humeral width; protarsi in males with long setae laterally

- Elytra about 2.0 times humeral width $\left({ }^{*}\right)$; protarsi in males without long setae laterally

38(37). Lateral tubercle of the prothorax distinctly longer than pedicel.

- Lateral tubercle of the prothorax small, clearly not longer than pedicel Mesestola Breuning, 1980

39(34). Body notably wide, elytra distinctly shorter than 2.0 times humeral width

- Body slender, elytra at least as long as 2.0 times humeral width Calliomorpha Lane, 1973

- Lateral tubercle of the prothorax very distinct. mucallia Galileo \& Martins, 2008

41(40). Pronotum with five distinct gibbosities Paracallia Martins \& Galileo, 1998 Pronotum, at most, with less than five distinct gibbosities $\left({ }^{* *}\right)$ ..Callia Audinet-Serville, 1835

${ }^{*}$ ) By the general appearance (body notably wide, lateral tubercle of the prothorax notably rounded, placed at posterior third), Colombicallia albofasciata Martins \& Galileo, 2006 does not belong to this genus.

(**) Apparently, Callia is not a monophyletic genus.

\section{Pteropliini Thomson, 1860 Epectasis Bates, 1866}

Epectasis was originally described in Pogonocherini for E. attenuata Bates, 1866 (= Saperda juncea Newman, 1840), from Brazil (Amazonas). Lacordaire (1872) transferred Epectasis to Estolini, currently a junior synonym of Desmiphorini. Bates (1880) included Epectasis in Ataxiini (currently, equal to Pteropliini): "I propose to include it in the "groupe" Ptéropliides of the 'Genera,' and the genera Epectasis, Amphicnaeia, and Aletretia, which have been hitherto placed in widely different groups." Aurivillius (1923) included Epectasis in Emphytoeciini, currently under synonymy of Pteropliini. Epectasis remains a problematic genus, with evident different species often being identified as a single species. This is notably true regarding E. juncea. It is possible to note in Bezark (2018) that some species with remarkable differences are being identified as E. juncea. However, it is not the scope of this work to deal with these problems in Epectasis, a genus needing a full revision.

\section{Epectasis mexicana Breuning, 1954 (Figs. 13-19)}

Epectasis mexicana Breuning, 1954: 6; 1961a: 27; 1961b: 223; Chemsak et al., 1992: 118 (checklist); Cools, 1993: 49 (type); Monné \& Giesbert, 1994: 208 (checklist); Monné, 1994: 64 (cat.); Noguera \& Chemsak, 1996: 405 (checklist); Monné, 2005: 641 (cat.); Monné \& Hovore, 2006: 295 (checklist); Monné, 2018: 871 (cat.).

Redescription of the holotype male (Figs. 17-19): Integument mostly dark brown, almost black on pronotum, more reddish on elytra and antennae; mouthparts dark reddish brown; antennomeres IV-IX (nine segments present on right antenna and seven on left one as the holotype has broken antennae) with basal whitish-brown ring due to the presence of small dense white pubescence in this part of segment.

Head: Frons, antennal tubercles and upper side of head moderately coarsely, abundantly punctate, covered with dense small reddish-brown pubescence interrupted in some rounded areas from which emerge an erect setae. Area behind upper eye lobes with light-brown pubescence obscuring integument; with a few long, erect yellowish setae close to eye. Area behind lower eye lobes finely punctate; with light-brown pubescence nearly obscuring integument; with long, erect, sparse lightbrown setae close to eye. Scape finely punctate with its maximum length at middle of its length, and then slightly curved internally to form at external apex rounded tooth; sides nearly parallel-sided toward apex and after first basal third. Antennomere III with dense light-brown pubescence basally, sparser, light-brown on remaining dorsal surface; with sparse light-brown setae around surface except on internal side where setae become longer and more numerous. Remaining antennomeres slenderer, with less setae when progressing to apex of antenna; basal part covered with rather dense whitish pubescence forming ring extending on $1 / 5$ of length of segment. Antennomere IV little bit longer than II+III combined and shorter than $\mathrm{V}+\mathrm{VI}$, length of segment $\mathrm{V}$ equal to $\mathrm{VI}$.

Thorax: Prothorax little bit longer than wide (including lateral tubercles); sides with small, distinct conical tubercle at middle with top directed to posterior part of body. Pronotum finely, densely punctate; with no well-defined elevation on dorsal surface occupying $2 / 3$ of anterior central part of pronotum; this elevation is excavated in its basal 
central part Y-shaped, but with very large base; covered with long light-brown pubescence obscuring integument from which emerge some sparse erect yellowish setae; same pubescence present on area before this elevation, along median line of pronotum and along posterior margin of dorsal part of pronotum; remaining surface covered with sparse and short light-brown pubescence not obscuring integument. Sides of prothorax very finely punctate; with two no well defined longitudinal lines of very light-brown pubescence covering integument; between those lines, on ventral side and on prosternal process, covered with sparse, short light-brown pubescence not obscuring integument; with some sparse erect yellowish setae. Elytra: Slightly, gradually narrowed from humerus at basal third, nearly parallel-sided at central third, slightly curved at posterior third; apex obliquely truncate; with surface punctate on first half of elytra, with sparse and deep punctures somewhat organized in rows, which are separate from each other by space larger than diameter of punctures, covered with very fine puncture; this string puncture tends to become smaller and sparser after $2 / 3$ of length of elytra; surface also with some no well defined longitudinal yellowish-white pubescent bands on basal half, except along suture with yellowish, gradually whiter pubescence along suture; area between yellowish-brown pubescent bands on basal half with brownish pubescence not obscuring integument; posterior half with irregular white pubescence not obscuring integument, with some erect, long, sparse white and brown setae; apex of elytra with dense fringe of curved light-brown setae. Legs: Coxae with sparse yellowish-brown pubescence not obscuring integument, with long, erect light-brown setae. Femora with yellowish-brown pubescence not obscuring integument, sparser on profemora, with short, decumbent white setae interspersed (more abundant on profemora); all femora with long, erect, moderately sparse uniformly golden-yel-
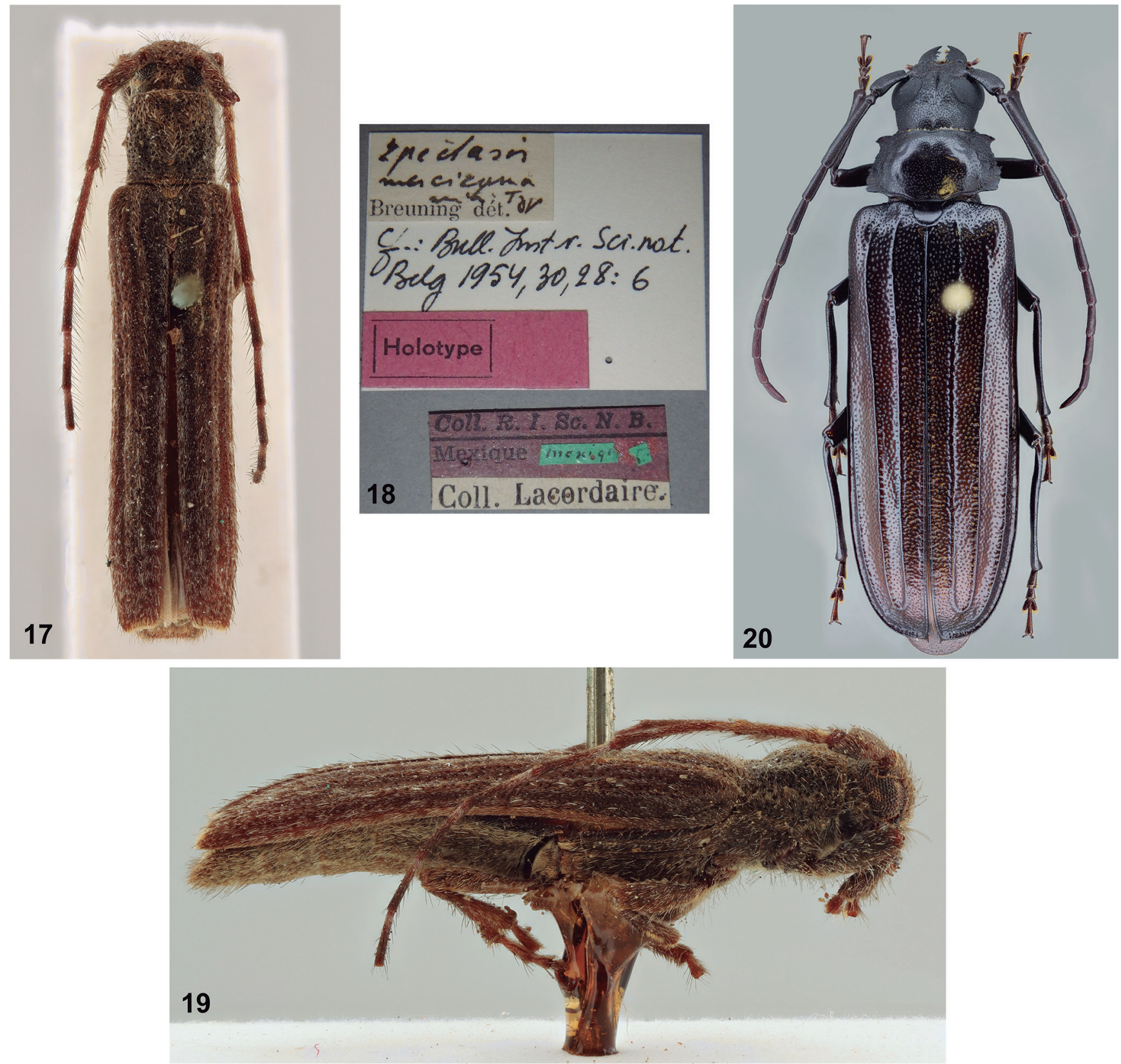

Figures 17-20. (17-19) Epectasis mexicana, holotype male: (17) Dorsal habitus; (18) Labels; (19) Lateral habitus. (20) Chorenta biramiguelus, female, dorsal habitus. 
lowish setae. Protibia with yellowish-brown pubescence basally, brownish on remaining surface; with both, short and long white setae interspersed (long setae dark basally). Meso- and metatibiae with yellowish-brown pubescence basally and distally (bristly distally), sparser, brownish, with decumbent white setae interspersed on central area.

Abdomen: Ventrites finely punctate; with light-golden pubescence nearly obscuring integument; with moderately long, yellowish white setae; some of these setae becoming slenderer, longer and oriented at $45^{\circ}$ on ventrite $\mathrm{V}$, emarginate centrally.

Dimensions (mm): Total length, 12.00; prothorax: length, 1.90; anterior width, 1.55; posterior width, 1.60; maximum width, 1.85; humeral width, 2.30; elytral length, 9.40. Total length of the holotype, $10.5 \mathrm{~mm}$.

Material examined: MEXICO, holotype male (RBINS; former Lacordaire collection). COLOMBIA (New country record), Norte de Santander: Road 70 (2,250 m; near Alto El Pozo; 08 02'19"N, 7302'13"W), 1 male, 21-24.VII.2017, V. Sinyaev col. (MZSP, former AKPC).

Remarks: Epectasis mexicana differs from E. juncea (Newman, 1840), E. attenuata Bates, 1866, and E. grossepunctata Breuning, 1942, especially by the elytra 3.4 times longer than head + prothorax. In the holotype of E.juncea, the elytra are about 2.8 times as long as head + prothorax; about 2.7 times in the holotype of E. attenuata Bates, 1866; and about 2.65 times in the holotype of E. grossepunctata Breuning, 1942. Additionally, the lateral tubercles of the prothorax are well-marked and conical in E. mexicana, while they are slightly marked and rounded in $E$. juncea.

\footnotetext{
Variations (Figs. 13-15) and additional features not studied in the holotype: Body somewhat wider in the holotype. Antennomeres IV-X with basal yellowish-brown ring, gradually reddish brown toward dark brown distal area (short on IV, reaching about midlength on remaining antennomeres). Punctures on frons moderately sparse; frons with dense yellowish-brown pubescence interspersed with brownish pubescence, slightly sparser toward clypeus, yellower adjacent to eyes. Area between antennal tubercles and upper eye lobes moderately coarsely, abundantly punctate; with brownish pubescence centrally, yellower laterally; remaining surface of vertex minutely, almost indistinct punctate; with yellowish-brown pubescence obscuring integument, except glabrous, longitudinal, narrow central area. Area behind upper eye lobes moderately finely, sparsely punctate close to eye, smooth on remaining surface; with yellowish-brown pubescence obscuring integument; area behind lower eye lobes coarsely, sparsely punctate. Genae very finely, transversely striate toward eye, smooth toward apex; with yellowish-brown pubescence not obscuring integument, especially toward apex, interspersed with decumbent, sparse white setae. Postclypeus with yellowish-brown pubescence not obscuring integument, with long, erect, sparse setae of same color. Labrum co-
}

planar with anteclypeus on posterior $2 / 3$, inclined on anterior third; with sparse yellowish-brown pubescence, longer, denser, yellower laterally; anterior margin with dense fringe of golden setae. Gulamentum with short, erect, sparse yellowish-white setae anteriorly. Distance between upper eye lobes 0.33 times length of scape; in frontal view, distance between lower eye lobes 0.73 times length of scape. Antennae 1.5 times elytral length, reaching elytral apex at distal third of antennomere IX; scape with brownish pubescence nearly obscuring integument except yellowish pubescence near apex, with short, sparse white setae interspersed; with long, erect, sparse dark setae ventrally (some of them whitish toward apex); antennomere III with dense yellowish pubescence basally, sparser, yellowish-brown on remaining dorsal surface, yellowish, not obscuring integument on outer surface, yellowish-white on inner surface, yellowish-brown, not obscuring integument ventrally; with short, sparse white setae interspersed; with long, erect, moderately sparse setae ventrally (setae dark basally, whitish toward apex). Antennal formula (ratio) based on length of antennomere III: scape $=0.88$; pedicel $=0.26$; IV $=1.76 ; \mathrm{V}=1.32$; $\mathrm{VI}=1.23 ; \mathrm{VII}=1.07 ; \mathrm{VIII}=1.00 ; \mathrm{IX}=0.91 ; \mathrm{X}=0.82 ; \mathrm{XI}=0.65$. Prothorax about as long as wide (including lateral tubercles). Sides of prothorax coarsely punctate. Prosternum with yellowish-brown pubescence not obscuring integument, with long, erect, white setae; prosternal process yellowish-brown pubescence not obscuring integument, with long, erect, moderately abundant yellowish-white setae. Mesoventrite with yellowish pubescence centrally, yellowish-brown laterally; with short, sparse, decumbent white setae laterally, and long setae of same color on central area. Mesoventral process widely, longitudinally sulcate centrally; apex emarginate; with yellowish-white pubescence not obscuring integument, with long, erect white setae interspersed. Mesanepisternum, mesepimeron, and metanepisternum with brownish pubescence not obscuring integument, with short, decumbent white setae interspersed. Metaventrite moderately coarsely, sparsely punctate laterally; with large, sub-triangular yellow pubescent macula on each side of posterior third, nearly obscuring integument; laterally with pubescence and setae as on metanepisternum, slightly longer, yellowish-white on remaining surface, with long, erect white setae interspersed. Scutellum with dense yellow pubescence except nearly glabrous central area. Elytra with ill-delimited, longitudinal yellowish-white pubescent bands on basal half.

\section{Prioninae \\ Callipogonini Thomson, 1861 Chorenta biramiguelus (Santos-Silva, 2004)} (Fig. 20)

Anacanthus biramiguelus Santos-Silva, 2004: 281.

Chorenta biramiguelus; Monné, 2006: 34 (cat.); Monné \& Hovore, 2006: 9 (checklist); Perger \& Santos-Silva, 2010: figs. 11, 13; Dalens et al., 2010: 218 (key); Monné \&Monné, 2016: 74 (holotype); Monné, 2018c: 77 (cat.). 
This species was described and remains known only from Brazil (Rondônia and Mato Grosso). Monné \& Hovore (2006) recorded: "Brasil (MG, RO)." Evidently, the state of Mato Grosso was incorrectly abbreviated as being "MG". Actually, the abbreviation of Mato Grosso is "MT", while "MG" means Minas Gerais. Dalens et al. (2010), apparently following Monné \& Hovore (2006), also incorrectly recorded "Brésil (Minas Gerais, Rondônia)."

Recently we examined two specimens from Peru that belong to this species (new country record).

Material examined: PERU, Loreto: Allpahuayo-Mishana National Reserve (lquitos-Nauta road, km 28), 2 females, XI.2017, E.L. Rojas col. (AKPC).

\section{ACKNOWLEDGMENTS}

The first and second authors express their sincere thanks to Anton Olegovich Kozlov for donating the holotypes to MZSP collection. The second author is grateful for the grant 2017/15283-9, São Paulo Research Foundation (FAPESP).

Contributions statement: All authors contributed equally.

Disclosure statement: No potential conflict of interest was reported by the authors.

\section{REFERENCES}

Aurivillius, C. 1923. Coleopterorum Catalogus, pars 74, Cerambycidae: Lamiinae. Berlin, W. Junk. p. 323-704.

Bates, H.W. 1880. Biologia Centrali-Americana, Insecta, Coleoptera. London. v. 5, p. 17-152.

Bezark, L.G. 2018. A photographic Catalog of the Cerambycidae of the New World. Available at: https://apps2.cdfa.ca.gov/publicApps/plant/ bycidDB/wsearch.asp?w=n. Access in: 10/2018.

Breuning, S. 1954. Nouvelles formes de Lamiaires (Septième partie). Bulletin de I'Institut de Sciences Naturelles de Belgique, 30(41): 1-23.

Breuning, S. 1961a. Révision des Pteropliini (Col., Cerambycidae). Pesquisas, Porto Alegre, 9: 5-60.

Breuning, S. 1961b. Catalogue des Lamiaires du Monde (Col., Cerambycidae). München, Museum G. Frey, Tutzing, 4: 183-284.

Carvalho, C.J.B. \& Almeida, E.A.B. 2011. Biogeografia da América do Sul: padrões \& processos. São Paulo, Roca., xii + 306p.

Chemsak, J.A.; Linsley, E.G. \& Noguera, F.A. 1992. Listados faunisticos de México. II. Los Cerambycidae y Disteniidae de Norteamérica, Centroamérica y las Indias Occidentales (Coleoptera). México, D.F., Universidad Nacional Autónoma. 204p.

Cools, J. 1993. Liste du matériel typique conservé dans les collections entomologiques de l'Institut Royal des Sciences Naturelles de Belgique. Coleoptera, Cerambycoidea, Cerambycidae. VIII. Sous-famille des Lamiinae. Documents de travail de l'Institut Royal des Sciences Naturelles de Belgique, 74: 1-115.

Dalens, P.-H.; Touroult, J. \& Tavakilian, G.L. 2010. Un nouveau prionien du plateau des Guyanes (Coleoptera, Cerambycidae, Prioninae). L'Entomologiste, 66(4): 181-185.
Galileo, M.H.M. \& Martins, U.R. 1991. Revisão da tribo Calliini (Coleoptera, (erambycidae, Lamiinae). Giornale Italiano di Entomologia, 5: 243-262.

Lacordaire, J.T. 1872. Histoire Naturelle des Insectes. Genera des Coléoptères, ou exposé méthodique et critique de tous les genres proposés jusqu'ici dans cet ordre d'insectes. Paris, Librairie Encyclopédique de Roret, v. 9, pt. 2, p. 411-930.

Lingafelter, S.W. 1998. The genera of Elaphidiini Thomson 1864 (Coleoptera: (erambycidae). Memoirs of the Entomological Society of Washington, 20: $1-118$.

Martins, U.R. 2005. Elaphidionini Thomson, 1864, pp. 1-394. In: Martins, U.R. (Org.). Cerambycidae Sul-Americanos (Coleoptera). Taxonomia. São Paulo, Sociedade Brasileira de Entomologia. v. 7, ii + 394p.

Martins, U.R. \& Galileo, M.H.M. 2007. Tribo Ibidionini, Subtribo Ibidionina, In: Martins, U.R. (Org.). CerambycidaeSul-Americanos (Coleoptera). Taxonomia. São Paulo, Sociedade Brasileira de Entomologia. v. 9, p. 177-330.

Monné, M.A. 1994. Catalogue of the Cerambycidae (Coleoptera) of the Western Hemisphere. Part XV. Subfamily Lamiinae: Tribes Onciderini, Laticraniini and Pteropliini. São Paulo, Sociedade Brasileira de Entomologia. 108p.

Monné, M.A. 2005. Catalogue of the Cerambycidae (Coleoptera) of the Neotropical Region. Part II. Subfamily Laminae. Zootaxa, 1023: 1-759.

Monné, M.A. 2006. Catalogue of the Cerambycidae (Coleoptera) of the Neotropical Region. Part III. Subfamilies Parandrinae, Prioninae, Anoplodermatinae, Aseminae, Spondylidinae, Lepturinae, Oxypeltinae, and addenda to the Cerambycinae and Lamiinae. Zootaxa, 1212: 1-244.

Monné, M.A. 2018a. Catalogue of the Cerambycidae (Coleoptera) of the Neotropical Region. Part I. Subfamily Cerambycinae. Available at: http:// cerambyxcat.com. Access in: 10/2018.

Monné, M.A. 2018b. Catalogue of the Cerambycidae (Coleoptera) of the Neotropical Region. Part II. Subfamily Lamiinae. Available at: http:// cerambyxcat.com. Access in: 10/2018.

Monné, M.A. 2018c. Catalogue of the Cerambycidae (Coleoptera) of the Neotropical Region. Part III. Subfamilies Lepturinae, Necydalinae, Parandrinae, Prioninae, Spondylidinaeand Families Oxipeltidae, Vesperidae and Disteniidae. Available at: http://cerambyxcat.com. Access in: 10/2018.

Monné, M.A. \& Giesbert, E.F. 1994. Checklist of the Cerambycidae and Disteniidae(Coleoptera) of the Western Hemisphere. Burbank, Wolfsgarden Books. 409p.

Monné, M.A. \& Hovore, F.T. 2006. A Checklist of the Cerambycidae, or longhorned wood-boring beetles, of the Western Hemisphere. California, Bio Quip Publications. 394p.

Monné, M.A. \& Monné, M.L. 2016. Checklist of Cerambycidae (Coleoptera) primary types of the Museu Nacional, Rio de Janeiro, Brazil, with a brief history of the collection. Zootaxa, 4110(1): 1-90.

Noguera, F.A. \& Chemsak, J.A. 1996. Cerambycidae (Coleoptera). In: Biodiversidad taxonomía, y biogeografía de artrópodos de Mexico: Hacia una síntesis de su conocimiento. México, D.F., Universidad Nacional Autónoma de México. 660p.

Perger, R. \& Santos-Silva, A. 2010. A new genus and species of Callipogonini, description of the male of Strongylaspis boliviana Monné \& Santos-Silva, 2003, and a new distributional record for Chorenta reticulata (Dalman, 1817) (Coleoptera, Cerambycidae). ZooKeys, 48: 29-38.

Santos-Silva, A. 2004. Nova espécie de Anacanthus do Brasil (Coleoptera, Cerambycidae, Prioninae, Callipogonini). Iheringia, Série Zoologia, 94(3): 281-283.

Santos-Silva, A.; Botero, J.P. \& Taboada-Verona, C. 2017. Three new species of Psyrassa Pascoe, 1866 (Coleoptera, Cerambycidae, Cerambycinae). Zootaxa, 4250(5): 494-500.

Tavakilian, G. \& Chevillotte, H. 2017. Titan: base de données internationales sur les Cerambycidae ou Longicornes. Available at: http://titan.gbif.fr/ index.html. Access in: 06/2018.

Toledo, V.H. 2005. Revisión taxonómica del género Psyrassa Pascoe (Coleoptera: Cerambycidae). Acta Zoológica Mexicana, 21(3): 1-64. 